\title{
PERBEDAAN UNSAFE ACTIONS ANTAR SHIFT KERJA PADA BAGIAN THREADING UNIT PRODUKSI I PT X DI SURABAYA
}

\author{
Jenius Setio Insanno \\ PT. Steel Pipe Industry of Indonesia (Spindo), Tbk \\ Jl. Kalibutuh 189-191, Surabaya 60173 \\ Email: InsannoJ@gmail.com
}

\begin{abstract}
ABSTARCT
PT. X is one of the companies that produces iron pipe in Indonesia. Unit of production I PT. X threading part used work shift system. Few months ago there was an accident happened to a night shift workers threading part, and it caused them to be rushed to the hospital and got medical help. The purpose of this research was to analyze the difference between unsafe action on work shifts threading of PT. X. This research was an observational descriptive study that used crossectional approach. The population of this research was all workers shift threading part of PT. X which were consisted of 30 people. Determination of the sample was using total population method that involved 30 people. This research used primary data based on the results of observation, interview and secondary data from the company. The results showed that the highest frequency of low unsafe action was at morning shift wich was 96,7\%. But it got decreased until 90\% at evening shift, and got decreased even more until 60\% at night shift. The difference of unsafe action can be caused by lack of supervision about safety at evening shift and night shift, and it can be caused by disturbed circadian rhytm of the workers'bodies. The company should increase the coordination about unsafe action supervision between HSE and related supervisor. Advice to workers, especially night shift workers, are optimizing the leisure time while waiting the materials and use it for getting some rest to keep their body away from fatigue conditions.
\end{abstract}

Keywords: unsafe action, work shift

\begin{abstract}
ABSTRAK
PT. X merupakan salah satu perusahaan yang memproduksi pipa besi di Indonesia. Unit produksi I PT. X bagian threading menerapkan sistem shift kerja. Pada beberapa bulan yang lalu telah terjadi kecelakaan pada pekerja shift malam bagian threading yang menyebabkan pekerja dilarikan ke rumah sakit untuk mendapatkan perawatan. Tujuan penelitian ini adalah menganalisis perbedaan unsafe action antar shift kerja bagian threading PT. X. Penelitian ini merupakan penelitian observasional deskriptif dengan pendekatan cross sectional. Populasi penelitian adalah seluruh pekerja shift bagian threading PT. X yang berjumlah 30 orang. Penentuan sampel menggunakan metode total populasi sehingga penelitian melibatkan 30 orang. Data yang digunakan adalah data primer berdasarkan hasil observasi dan wawancara serta data sekunder dari perusahaan. Hasil penelitian menunjukkan bahwa kejadian unsafe action yang menyatakan rendah memiliki frekuensi terbesar pada shift pagi yaitu 96,7\%, namun unsafe action yang menyatakan rendah mengalami penurunan pada shift kerja sore menjadi $90 \%$ dan mengalami penurunan kembali pada shift malam menjadi $60 \%$. Perbedaan dapat disebabkan oleh kurangnya pengawasan tentang keselamatan yang dilakukan pada shift sore dan malam hari serta terganggunya circadian rhytm pada tubuh. Saran untuk perusahaan adalah dengan meningkatkan koordinasi antara pihak HSE dengan supervisor terkait dengan pengawasan terhadap unsafe action. Saran kepada pekerja khususnya yang bekerja pada shift malam dapat mengoptimalkan waktu luang ketika menunggu bahan yang akan dipahat dengan beristirahat sejenak untuk menjaga kondisi tubuh agar tidak mengalami kelelahan.
\end{abstract}

Kata kunci: unsafe action, shift kerja

\section{PENDAHULUAN}

Pada era modernisasi saat ini, pertumbuhan dan perkembangan teknologi semakin pesat, hal ini diikuti dengan perkembangan di bidang industri, terutama di negara-negara berkembang. Hal tersebut mengakibatkan bertambahnya jumlah perusahaan baik berskala kecil, menengah maupun besar. Suatu perusahaan sering timbul permasalahan yang berkaitan dengan kecelakaan kerja, penyakit akibat kerja serta dampak negatif industri yang dapat merugikan lingkungan. Perkembangan dan pertumbuhan yang semakin meningkat pada bidang perindustrian dapat meningkatkan pula risiko terjadinya dampak-dampak negatif pada lingkungan kerja. sehingga dirasa penting akan adanya peranan dari keselamatan dan kesehatan kerja khususnya pada negara berkembang seperti Indonesia. 
Angka kecelakaan kerja yang terjadi di Indonesia masih tergolong cukup tinggi. Data dari Jamsostek (2012) menyebutkan bahwa angka kasus kecelakaan kerja di Indonesia pada tahun 2007 terdapat 83.714 kasus kecelakaan kerja, pada tahun 2008 terdapat 94.736 kasus, tahun 2009 terdapat 96.314 kasus kecelakaan kerja, tahun 2010 ada 98.711 kasus kecelakaan kerja, dan pada tahun 2011 terdapat 99.491 kasus kecelakaan kerja. Dengan demikian rata-rata sehari terjadi 414 kasus kecelakaan kerja di Indonesia.

Pemerintah telah melakukan upaya dalam menanggapi tingginya kecelakaan kerja yang ada di Indonesia yaitu dengan pembuatan perundangundangan, antara lain Undang-Undang No. 1 Tahun 1970 tentang keselamatan kerja. Pada UU No. 1 Tahun 1970 tentang keselamatan kerja telah diatur banyak hal, antara lain syarat-syarat dalam keselamatan kerja, pengawasan, pembinaan terhadap tenaga kerja (termasuk pada tenaga kerja baru harus menjelaskan kondisi lingkungan kerja, bahaya yang dapat terjadi, alat perlindungan diri yang harus dipakai, dan cara serta sikap dalam menjalankan pekerjaannya), P2K3, kewajiban dan hak kerja, kewajiban pengurus, dan kewajiban-kewajiban saat memasuki tempat kerja.

Upaya yang dilakukan tidak hanya dari pemerintah, tetapi juga dari perusahaan. Salah satu upaya pengendalian yang dapat dilakukan oleh perusahaan ialah dengan pengaturan shift kerja. Menurut Wijono (2006), pekerja yang mengalami stres kerja rendah mempunyai jam kerja/minggu antara 37 hingga 40 jam, sedangkan pekerja yang mengalami stres kerja sedang mempunyai jumlah jam kerja/minggu antara 41 hingga 60 jam. Sebaliknya, pekerja yang mengalami stres kerja tinggi mempunyai jumlah jam kerja/minggu antara 61 hingga 71 jam. Shift kerja dapat berperan penting terhadap permasalahan pada manusia yang dapat meluas menjadi gangguan tidur, gangguan fisik dan psikologi, serta gangguan sosial serta kehidupan keluarga, shift juga dapat mempengaruhi beberapa perubahan fisik dan psikologi tubuh diantaranya adalah kelelahan (Wijaya, 2006).

Menurut penelitian Wijaya (2006), pada shift pagi dan shift malam terdapat perbedaan tingkat kelelahan kerja. Antar kedua shift, antara shift sore dan shift malam juga terdapat perbedaan tingkat kelelahan kerja. Tingkat kelelahan kerja pada shift pagi lebih rendah dari pada shift sore, dan tingkat kelelahan kerja shift sore lebih rendah dari pada shift malam. Tingkat kelelahan kerja pada shift pagi lebih rendah dari pada shift malam. Pekerja pada shift malam memiliki risiko $28 \%$ lebih tinggi mengalami cidera atau kecelakaan. Faktor kelelahan yang terjadi dalam seorang pekerja menjadi salah satu penyebab dari timbulnya unsafe action yang menjadi salah satu faktor terjadinya kecelakaan kerja (Lientje, 2008).

Menurut Heinrich dalam Budiono (2003) terjadinya kecelakaan kerja dipengaruhi oleh 2 (dua) penyebab langsung yaitu unsafe action (tindakan tidak aman) dan unsafe conditions (kondisi tidak aman). Tindakan tidak aman adalah suatu tindakan yang tidak memenuhi keselamatan sehingga berisiko menyebabkan kecelakaan kerja. Sedangkan kondisi tidak aman adalah keadaan lingkungan yang tidak aman dan berisiko menyebabkan kecelakaan kerja (Gatipuri, 2011). Dalam studi yang dilakukan Heinrich tahun 1928 pada 75 ribu kasus kecelakaan industri didapatkan bahwa $88 \%$ disebabkan oleh tindakan tidak aman, $10 \%$ oleh kondisi tidak aman dan $2 \%$ tidak dapat dihindarkan seperti bencana alam (Ramli, 2010).

PT. X merupakan sebuah perusahaan penghasil pipa yang terbuat dari baja. Jenis pipa yang dihasilkan diantaranya pipa baja hitam, pipa baja stainless dan pipa baja stall putih. PT. X memiliki 5 unit produksi yang letaknya tersebar di beberapa kota. Untuk proses pembuatan pipa pada unit produksi I harus melewati beberapa proses produksi yang cukup panjang, diantaranya proses uncoiler, milling, endfacing, hidrotes, cleaning, galvanizing, pelurus, threading, annealing dan masih banyak lagi. Pada satu proses terdapat antara 3-5 orang tiap shift kerja. Pada PT. X diberlakukan 3 jenis shift kerja, yaitu jam kerja pagi pukul 07.00-15.00, jam kerja sore pukul 15.00-23.00, dan jam kerja malam pukul 23.00-07.00.

Hasil wawancara kepada kepala departemen personalia dan HSE unit produksi I di PT. X. Diketahui bahwasanya kecelakaan yang terjadi pada unit produksi I masih tergolong cukup tinggi. Dari kecelakaan ringan seperti terpeleset, terbentur material, mata kemasukan gram, kecelakaan berat seperti cedera tangan yang tertusuk pipa besi, terpental oleh mesin, bahkan hingga kecelakaan fatal yang menyebabkan kematian. Kecelakaan terbaru yang terjadi pada proses threading yaitu seorang pekerja yang tersangkut mesin sehingga menyebabkan cedera luka berat pada punggung sehingga langsung dirujuk ke rumah sakit. Kecelakaan yang tergolong berat tersebut terjadi pada shift kerja malam hari. Kecelakaan pada shift kerja malam juga pernah terjadi pada proses 
threading berupa tersandung, terpeleset dan mata kemasukan gram.

Tujuan dari penelitian ini adalah membandingkan tingkat unsafe action antara shift pagi, sore, dan malam pada bagian threading unit produksi I PT X.

\section{METODE}

Penelitian ini dilihat dari sistem analisisnya termasuk Jenis penelitian adalah observasional deskriptif, yaitu pendekatan penelitian yang dalam pengumpulan data tanpa ada perlakuan apa pun pada responden. Penelitian mempelajari tentang unsafe action pada bagian threading unit produksi I PT. X serta menganalisis perbedaan antar shift kerja secara observasi. Menurut waktunya, termasuk penelitian cross sectional karena pengamatan terhadap variabel dilakukan pada saat atau waktu periode tertentu saja. Data yang didapatkan pada penelitian ini merupakan data primer dengan melakukan observasi dan wawancara pada tenaga kerja dan lingkungan kerja, serta data sekunder yang didapatkan dari perusahaan.

Objek dari penelitian ini adalah 30 pekerja pada PT. X pada bagian threading unit produksi I yang terbagi menjadi 3 shift kerja dengan masing-masing shift kerja sebanyak 10 pekerja. Teknik pengambilan sampel menggunakan total populasi yaitu 30 pekerja pada bagian threading unit produksi I PT. X.

Variabel yang diteliti dalam penelitian ini antara lain adalah tingkat unsafe action yang dilakukan oleh pekerja dan shift kerja pada bagian threading Unit Produksi I PT. X.

Data yang dikumpulkan dalam penelitian ini adalah data primer dan sekunder. Data primer didapatkan melalui observasi yang dilakukan kepada setiap pekerja pada shift kerja pagi, sore, dan malam untuk unsafe action. Observasi dilakukan oleh peneliti dengan meminta bantuan kepada rekan peneliti di mana sebelumnya sudah dijelaskan mengenai tata cara melakukan observasi. Data primer juga didapatkan melalui wawancara pada responden yang akan dilakukan pada saat istirahat. Data sekunder meliputi gambaran umum perusahaan, lokasi perusahaan, struktur organisasi, ketenagakerjaan, jam kerja dan kecelakaan kerja. Analisis data yang digunakan dalam penelitian ini menggunakan analisis univariat dan bivariat. Analisis univariat digunakan untuk melihat distribusi frekuensi dan persentase dari masing-masing variabel yang meliputi unsafe action. Informasi yang diperoleh akan disajikan dalam bentuk tabel dan dinarasikan. Analisis bivariat digunakan untuk mengetahui keterkaitan antara dua variabel. Perbedaan unsafe action antara shift pagi, sore, dan malam hari akan dianalisis secara deskriptif dengan melihat distribusi frekuensi unsafe action, lalu dibandingkan antar shift kerja.

\section{HASIL}

\section{Unsafe Action}

Unsafe action yang diteliti meliputi 9 poin dari unsafe action yang dapat terjadi pada bagian threading. Hasil dari observasi dan wawancara yang telah dilakukan pada pekerja shift pagi dapat dilihat pada Tabel 1.

Berdasarkan Tabel 1 diketahui bahwa dari hasil observasi yang dilakukan terkait poin 1-8 dan wawancara terkait poin 9 yang dilakukan pekerja menunjukkan unsafe action yang paling banyak dilakukan oleh pekerja pada shift pagi adalah tidak menggunakan Alat Pelindung Diri. Sedangkan unsafe action yang memiliki frekuensi terendah adalah menempatkan atau menyusun secara salah. Hasil dari observasi dan wawancara yang telah dilakukan pada pekerja shift sore dapat dilihat pada Tabel 2.

Berdasarkan Tabel 2 diketahui bahwa dari hasil observasi yang dilakukan terkait poin 1-8 dan wawancara terkait poin 9 yang dilakukan pada pekerja menunjukkan unsafe action yang paling banyak dilakukan oleh pekerja pada shift sore adalah tidak menggunakan Alat Pelindung Diri. Sedangkan unsafe action yang memiliki frekuensi terendah adalah menempatkan/menyusun secara salah.

Hasil dari observasi dan wawancara yang telah dilakukan pada pekerja shift malam dapat dilihat pada Tabel 3 terkait dengan distribusi unsafe action yang dilakukan oleh pekerja shift kerja malam bagian threading PT. X unit produksi I pada tahun 2015.

Berdasarkan Tabel 3 diketahui bahwa dari hasil observasi yang dilakukan terkait poin 1-8 dan wawancara terkait poin 9 yang dilakukan pada pekerja menunjukkan unsafe action yang paling banyak dilakukan oleh pekerja pada shift malam adalah tidak menggunakan Alat Pelindung Diri. Sedangkan unsafe action yang memiliki frekuensi terendah adalah menempatkan/menyusun secara salah.

Unsafe action yang diteliti akan dikategorikan menjadi 3 kategori yaitu rendah, sedang dan tinggi. 
Tabel 1. Distribusi Frekuensi Unsafe Action yang Dilakukan Pekerja Pada Shift Kerja Pagi PT. X Unit Produksi I Bagian Threading Tahun 2015

\begin{tabular}{llcccccc}
\hline \multirow{2}{*}{ No Unsafe Action } & \multicolumn{3}{c}{ Safe } & \multicolumn{2}{c}{ Unsafe } & \multicolumn{2}{c}{ Total } \\
\cline { 2 - 8 } & & $\sum$ & $\mathbf{\%}$ & $\sum$ & $\mathbf{\%}$ & $\sum$ & $\mathbf{\%}$ \\
\hline 1 & Gagal untuk mengamankan & 27 & 90 & 3 & 10 & 30 & 100 \\
2 & Bekerja dengan kecepatan yang salah & 26 & 86,7 & 4 & 13,3 & 30 & 100 \\
3 & Menggunakan alat yang rusak & 29 & 96,7 & 1 & 3,3 & 30 & 100 \\
4 & Tidak menggunakan APD & 3 & 10 & 27 & 90 & 30 & 100 \\
5 & Menempatkan/menyusun secara salah & 30 & 100 & 0 & 0 & 30 & 100 \\
6 & Pengangkatan secara salah & 29 & 96,7 & 1 & 3,3 & 30 & 100 \\
7 & Mengambil posisi yang salah & 23 & 90 & 7 & 10 & 30 & 100 \\
8 & Bercanda saat bekerja & 24 & 80 & 6 & 20 & 30 & 100 \\
9 & Bekerja di bawah pengaruh obat-obatan dan alkohol. & 29 & 96,7 & 1 & 3,3 & 30 & 100 \\
\hline
\end{tabular}

Sumber: Data primer tahun 2015

Tabel 2. Distribusi Frekuensi Unsafe Action yang Dilakukan Pekerja Pada Shift Kerja Sore PT. X Unit Produksi I Bagian Threading Tahun 2015

\begin{tabular}{llrrrrcc}
\hline \multirow{2}{*}{ No } & \multicolumn{1}{c}{ Unsafe Action } & \multicolumn{2}{c}{ Safe } & \multicolumn{2}{c}{ Unsafe } & \multicolumn{3}{c}{ Total } \\
\cline { 3 - 7 } & & $\sum$ & $\mathbf{\%}$ & $\sum$ & $\mathbf{\%}$ & $\sum$ & $\mathbf{\%}$ \\
\hline 1 & Gagal untuk mengamankan & 25 & 83,3 & 5 & 16,7 & 30 & 100 \\
2 & Bekerja dengan kecepatan yang salah & 23 & 76.7 & 7 & 23,3 & 30 & 100 \\
3 & Menggunakan alat yang rusak & 29 & 96,7 & 1 & 3,3 & 30 & 100 \\
4 & Tidak menggunakan APD & 2 & 6,7 & 28 & 93,3 & 30 & 100 \\
5 & Menempatkan/menyusun secara salah & 30 & 100 & 0 & 0 & 30 & 100 \\
6 & Pengangkatan secara salah & 27 & 90 & 3 & 10 & 30 & 100 \\
7 & Mengambil posisi yang salah & 19 & 63,3 & 11 & 36,7 & 30 & 100 \\
8 & Bercanda saat bekerja & 17 & 56,7 & 13 & 43,3 & 30 & 100 \\
9 & Bekerja di bawah pengaruh obat-obatan dan alkohol. & 29 & 96,7 & 1 & 3,3 & 30 & 100 \\
\hline
\end{tabular}

Sumber: Data primer tahun 2015

Tabel 3. Distribusi Frekuensi Unsafe Action yang Dilakukan Pekerja Pada Shift Kerja Malam PT. X Unit Produksi I Bagian Threading Tahun 2015

\begin{tabular}{llcccccc}
\hline \multirow{2}{*}{ No } & \multicolumn{1}{c}{ Unsafe Action } & \multicolumn{3}{c}{ Safe } & \multicolumn{2}{c}{ Unsafe } & \multicolumn{2}{c}{ Total } \\
\cline { 2 - 7 } & & $\sum$ & $\mathbf{\%}$ & $\sum$ & $\mathbf{\%}$ & $\sum$ & $\mathbf{\%}$ \\
\hline 1 & Gagal untuk mengamankan & 27 & 90 & 3 & 10 & 30 & 100 \\
2 & Bekerja dengan kecepatan yang salah & 26 & 86,7 & 4 & 13,3 & 30 & 100 \\
3 & Menggunakan alat yang rusak & 29 & 96,7 & 1 & 3,3 & 30 & 100 \\
4 & Tidak menggunakan APD & 3 & 10 & 27 & 90 & 30 & 100 \\
5 & Menempatkan/menyusun secara salah & 30 & 100 & 0 & 0 & 30 & 100 \\
6 & Pengangkatan secara salah & 29 & 96,7 & 1 & 3,3 & 30 & 100 \\
7 & Mengambil posisi yang salah & 23 & 90 & 7 & 10 & 30 & 100 \\
8 & Bercanda saat bekerja & 24 & 80 & 6 & 20 & 30 & 100 \\
9 & Bekerja di bawah pengaruh obat-obatan dan alkohol. & 29 & 96,7 & 1 & 3,3 & 30 & 100 \\
\hline
\end{tabular}

Sumber: Data primer tahun 2015 
Tabel 4. Distribusi Frekuensi Unsafe Action Pada Shift Kerja Pagi, Sore, dan Malam di PT. X Unit Produksi I Bagian threading Tahun 2015

\begin{tabular}{lcccccc}
\hline \multirow{2}{*}{ Unsafe Action } & \multicolumn{7}{c}{ Shift Kerja } \\
\cline { 2 - 7 } & Pagi & $\mathbf{\%}$ & Sore & $\mathbf{\%}$ & Malam & \% \\
\hline Rendah & 29 & 96,7 & 21 & 90 & 18 & 60 \\
Sedang & 1 & 3,3 & 9 & 10 & 11 & 36,7 \\
Tinggi & 0 & 0 & 0 & 0 & 1 & 3,3 \\
\hline Total & 30 & 100 & 30 & 100 & 30 & 100 \\
\hline
\end{tabular}

Tabel 4 terkait distribusi frekuensi unsafe action berdasarkan kategori rendah, sedang, dan tinggi pada pekerja shift kerja pagi, sore, dan malam di bagian threading PT. X unit produksi I pada tahun 2015.

Berdasarkan Tabel 4 dapat diketahui bahwa frekuensi hasil observasi responden yang menyatakan unsafe action rendah terbanyak terdapat pada shift pagi, namun mengalami penurunan pada shift sore dan shift malam. Sebaliknya frekuensi observasi responden yang menyatakan unsafe action sedang mengalami peningkatan yaitu pada shift sore dan shift malam.

\section{Shift Kerja}

Sistem shift kerja yang diterapkan pada PT. X Unit Produksi I bagian threading adalah sistem shift kerja yang dibagi menjadi 3 shift, yaitu shift I (pagi), shift II (sore), dan shift III (malam). Untuk setiap shift kerja diperlukan waktu selama 8 jam/ hari. Setiap shift kerja diberikan kesempatan untuk beristirahat selama setengah jam untuk makan dan beribadah. Jam istirahat untuk shift pagi, istirahat diberikan pada pukul 12.00 , untuk shift sore pada pukul 18.00, sedangkan istirahat untuk shift malam diberikan pada pukul 04.00.

Pengaturan jadwal shift kerja di PT. X Unit Produksi I bagian threading adalah sistem 5 hari kerja dengan total $40 \mathrm{jam} /$ minggu serta dilakukan pergantian shift pada tiap minggunya. Pekerja pada minggu pertama termasuk dalam grup shift pagi, minggu depan pekerja akan berpindah menjadi grup shift malam. Pergantian tersebut juga berlaku pada grup yang lain dari grup shift sore ke grup shift pagi, grup shift malam ke grup shift, begitu seterusnya untuk minggu-minggu selanjutnya.

Waktu kerja sistem shift kerja adalah sebagai berikut:Shift I (pagi), 07.00 WIB-15.00 WIB; Shift II (sore), 15.00 WIB-23.00 WIB; Shift III (malam), 23.00 WIB-07.00 WIB
Bagi pekerja shift diwajibkan hadir setengah jam sebelum pergantian shift berlangsung. Pada hari jum'at setiap pergantian shift mengalami kemunduran waktu setengah jam dikarenakan pada shift pagi terdapat perpanjangan waktu istirahat yang gunakan untuk melakukan sholat jum'at.

Peneliti melakukan penelitian pada bagian threading dan diketahui bahwa pengawasan terkait dengan K3 hanya terdapat pada shift pagi saja. Dikarenakan pengawas terkait dengan K3 hanya memiliki jam kerja dari jam 8 pagi hingga jam 4 sore. Meskipun pada setiap shift kerja terdapat pengawas dari departemen produksi, tapi pengawas hanya melakukan pengawasan terkait dengan hasil dari produksi.

\section{PEMBAHASAN}

Unsafe action pada penelitian ini adalah perilaku berbahaya yang dilakukan oleh pekerja pada bagian threading yang dapat berisiko menyebabkan kecelakaan kerja. Menurut Heinrich pada tahun 1930 (Suma'mur, 2009), menunjukkan bahwa kecelakaan kerja paling besar diakibatkan oleh perilaku tidak aman yaitu sebesar $88 \%$. Berdasarkan hal tersebut maka dapat dikatakan bahwa perilaku yang tidak aman memiliki andil besar dalam terjadinya sebuah kecelakaan kerja. Menurut teori dari Bird dan Germain yang dikembangkan dari teori domino Heinrich (Budiono, 2003) menjelaskan bahwa perilaku yang tidak aman dapat disebabkan oleh basic cause yaitu terdiri dari faktor personal dan faktor pekerjaan.

Berdasarkan hasil penelitian unsafe action pada bagian threading PT X pada Tabel 1, Tabel 2, dan Tabel 3 diketahui bahwa poin unsafe action yang mengalami perbedaan antara shift pagi, shift sore, dan shift malam adalah gagal untuk mengamankan, bekerja dengan kecepatan yang salah, tidak menggunakan APD, pengangkatan secara salah, 
mengambil posisi yang salah, bercanda saat bekerja, dan bekerja di bawah pengaruh obat-obatan dan alkohol.

Jika ditinjau menurut Budiono (2003), bahwa tindakan tidak aman berupa kegagalan dalam mengamankan yang terjadi pada bagian theading dapat disebabkan karena faktor personal yaitu kurangnya pengetahuan dan keterampilan pekerja dalam bidang keselamatan dan kesehatan kerja. Hal ini tergambarkan pada kurangnya rasa awareness atau kewaspadaan pekerja ketika melakukan pekerjaan.

Kurangnya kewaspadaan dapat timbul akibat ketidaktahuan pekerja akan bahaya yang ada pada pekerjaan yang dilakukan. Menurut Notoatmodjo (2012), dalam teori Green terdapat 3 faktor yang dapat memengaruhi tindakan seseorang, salah satunya ialah faktor predisposing yaitu pengetahuan, sikap, keyakinan, dan kepercayaan yang dimiliki oleh seseorang.

Kegagalan dalam mengamankan akan terjadi apabila seseorang yang kurang memiliki pengetahuan seputar keselamatan dan kesehatan kerja, misalnya saja pengetahuan terkait dengan bahaya yang ada pada pekerjaannya. Apabila seseorang tersebut memiliki pengetahuan tentang bahaya yang terdapat pada pekerjaan yang dilakukan, maka seseorang tersebut akan berusaha untuk menghindari bahaya yang akan terjadi pada dirinya. Sebaliknya, apabila seseorang tersebut tidak mengetahui bahwa terdapat bahaya pada pekerjaannya, otomatis seseorang tersebut juga tidak dapat melakukan pencegahan agar terhindar dari bahaya yang ada pada pekerjaannya.

Selain faktor pengetahuan, kegagalan dalam mengamankan juga dapat terjadi akibat kurangnya kemampuan fisik dari pekerja. Hal ini juga berkaitan dengan kewaspadaan dalam menanggulangi bahaya yang ada pada pekerjaan. Menurut hasil penelitian yang dilakukan Kusumaningsari, dkk (2014) bahwa kelelahan dapat berpengaruh terhadap tingkat kewaspadaan yang dimiliki oleh pekerja.

Tentunya kelelahan tersebut yang mendasari perbedaan antara shift pagi, sore, dan malam hari. Diketahui bahwa ketika beranjak menuju malam hari, tubuh akan mengalami fase thropotropic terjadi pada malam hari ketika fungsi dari tubuh mengalami penurunan dan kelelahan atau membutuhkan istirahat/pemulihan (Maurits, 2010).

Berdasarkan hasil observasi yang dilakukan pada pekerja bagian threading juga diketahui bahwa terdapat perbedaan pada poin unsafe action berupa bekerja dengan kecepatan yang salah antara shift pagi, shift sore, dan shift malam hari. Bekerja dengan kecepatan yang salah banyak ditemukan pada pekerja pada saat berjalan melewati sela-sela mesin dan tidak menggunakan jalan yang telah disediakan oleh perusahaan.

Perbedaan dapat terjadi akibat dari pekerja yang merasa kelelahan dan ingin secepatnya mencapai tujuan. Sehingga pada saat berjalanpun pekerja lebih memilih untuk melewati jalan pintas dari melewati jalan yang telah disediakan dikarenakan jalan yang disediakan dianggap lebih jauh dan lebih membutuhkan tenaga daripada melewati jalan pintas yang lebih praktis.

Perbedaan unsafe action antar shift kerja berupa bekerja dengan kecepatan yang salah juga dilandasi karena pengawasan terkait dengan keselamatan dan kesehatan kerja hanya dilakukan pada shift pagi, sedangkan pada shift sore dan shift malam hari tidak ada pengawasan terkait dengan keselamatan dan kesehatan kerja. Sehingga pekerja pada shift sore dan shift malam hari terkesan tidak mematuhi peraturan yang terdapat pada perusahaan bahwa pekerja diharuskan berjalan melalui jalan yang telah tersedia.

Berdasarkan observasi yang telah dilakukan pada bagian threading diketahui bahwa hampir seluruh pekerja tidak menggunakan APD secara lengkap baik pada shift pagi, shift sore dan shift malam. Sebagaimana dijelaskan pada SOP bagian threading bahwa pekerja wajib menggunakan APD yakni menggunakan sepatu safety, helm safety, sarung tangan, dan earplug. Dari hasil penelitian, pekerja kebanyakan hanya menggunakan sepatu safety dan helm safety, sehingga tak jarang pekerja menanggalkan sarung tangan dan earplug ketika melakukan pekerjaan.

Menurut Occupational Safety and Health Administration (OSHA) Alat pelindung diri atau APD adalah alat yang digunakan untuk melindungi pekerja dari luka atau penyakit yang diakibatkan oleh adanya kontak dengan bahaya di tempat kerja, baik yang bersifat kimia, fisik, elektrik, biologis, mekanik, dan lainnya. Dalam hirarki pengendalian kecelakaan, penggunaan APD merupakan pilihan paling terakhir digunakan apabila pada tahap awal pengendalian tidak dapat dilakukan secara maksimal.

Banyak faktor yang dapat mempengaruhi pekerja sehingga tidak menggunakan APD secara tepat. Menurut teori dari Bird dan Germain (Budiono, 2003) terjadinya tindakan tidak aman termasuk tidak menggunakan APD secara tepat 
dapat dipengaruhi oleh faktor personal dan faktor pekerjaan. Faktor personal dalam kasus ini dapat berupa kurangnya pengetahuan tentang pentingnya menggunakan APD. Pengetahuan merupakan domain yang sangat penting untuk terbentuknya tindakan seseorang. Seseorang yang memiliki pengetahuan yang baik akan cenderung memiliki sikap yang baik. akan melakukan tindakan yang menurutnya dapat bermanfaat bagi dirinya, termasuk juga dalam hal penggunaan APD secara tepat. Namun pengetahuan yang baik jika tidak didukung oleh motivasi untuk menerapkan pengetahuannya juga akan sia-sia.

Motivasi yang kurang juga termasuk dalam faktor personal yang dapat menyebabkan tindakan yang tidak aman. Motivasi terbentuk dari beberapa hal seperti lingkungan pekerjaan atau rangsangan lain berupa beberapa perlakuan (Iqbal, 2014). Seseorang akan memiliki motivasi yang baik apabila berada dalam lingkungan yang baik pula. Dalam hal penggunaan APD, Apabila lingkungan pekerjaan sudah terbiasa tidak menggunakan APD akan membuat rendahnya motivasi pekerja untuk menerapkan pengetahuan yang dimiliki tentang menggunakan APD. Kebiasaan yang ada pada lingkungan kerja juga tak lepas dari faktor pekerjaan yang menjadi penyebab dasar terjadinya tindakan tidak aman.

Faktor pekerjaan yang dimaksud adalah tidak cukupnya pengawasan yang dilakukan terkait dengan penggunaan APD. Pengawasan pada pekerja dapat difungsikan sebagai pendorong agar pekerja dapat membiasakan diri untuk selalu menggunakan APD secara tepat. Namun, dalam beberapa hal pengawasan yang kurang terencana dengan baik juga dapat mempengaruhi pekerja dalam menggunakan APD. Pekerja hanya akan menggunakan APD apabila merasa diawasi atau mengetahui bahwa sedang ada pengawasan.

Pengawasan terkait dengan keselamatan dan kesehatan kerja pada perusahaan hanya dilakukan pada shift pagi saja, sedangkan untuk semua shift hanya terdapat pengawasan terkait dengan hasil produksi. Sehingga pada shift sore dan malam tidak ada faktor pendorong pekerja untuk selalu menggunakan APD secara tepat. Seharusnya perlu dilakukan koordinasi antara pengawas HSE dengan pengawas bagian produksi agar pengawasan terkait keselamatan dan kesehatan kerja juga dapat dilakukan pada shift sore dan shift malam.

Selain kurangnya pengawasan, faktor pekerjaan yang dapat mempengaruhi tindakan penggunaan APD ialah ketersediaan sarana yang dalam hal ini adalah APD. Penggunaan APD secara tepat tidak akan terlaksana apabila tidak adanya ketersediaan dari APD itu sendiri. Selain itu juga dapat dikarenakan tidak adanya sistem pemberian tanda peringatan dan penggunaan APD pada tempat kerja sehingga baik pada saat tidak adanya pengawasan, terdapat pengingat bagi pekerja agar mematuhi peraturan dari perusahaan yakni kewajiban menggunakan APD ketika bekerja.

Terjadinya unsafe action berupa pengangkatan secara salah juga mengalami perbedaan antar shift kerja. Pengangkatan secara salah yang paling sering terjadi pada pekerja ialah mengangkat/menggeser seikat pipa menggunakan tangan. Padahal menurut peraturan perusahaan, seikat pipa harus diangkat menggunakan over head crane (OHC) yang tersedia dengan bantuan operator OHC. Namun menurut pekerja hal tersebut dirasa kurang efisien jika hanya untuk menggeser seikat pipa harus menunggu operator OHC.

Pengawasan yang dilakukan oleh pengawas pihak HSE berperan penting agar pekerja mematuhi peraturan yang berlaku pada perusahaan. Karena pengawasan tersebut berperan sebagai motivasi pekerja agar nantinya tidak mendapatkan teguran dan peringatan. Sehingga pekerja akan terus mematuhi peraturan yang berlaku khususnya terkait dengan masalah keselamatan dan kesehatan kerja.

Hasil observasi juga menunjukkan adanya perbedaan antar shift kerja terkait unsafe action berupa mengambil posisi secara salah. Pada saat observasi tak sedikit dari pekerja yang memposisikan badan terlalu dekat dengan mesin pahat. Hal tersebut dapat memicu kecelakaan kerja berupa $\mathrm{Hal}$ ini dapat disebabkan oleh kurangnya pengetahuan dan keahlian dari pekerja terkait dengan bahaya apabila dirinya memposisikan diri terlalu dekat dengan mesin.

Kurangnya pengetahuan dan keahlian pekerja terkait dengan bahaya apabila terlalu dekat dengan mesin akan mempengaruhi sikap serta tindakan yang dilakukan oleh pekerja. Dikarenakan semakin rendah pengetahuannya akan berdampak pada pekerja dalam menyikapi bahaya yang ada apabila terlalu dekat dengan mesin.

Memposisikan diri terlalu dekat dengan mesin dapat disebabkan karena tidak adanya tanda peringatan pada mesin, seperti jangan terlalu dekat pada mesin pahat dan lain sebagainya. Tanda peringatan dapat berfungsi sebagai pengingat pekerja agar tidak melakukan perbuatan yang tidak aman termasuk memposisikan diri terlalu dekat 
dengan mesin pahat. Hal ini diperkuat oleh teori perubahan perilaku dari green (Notoatmodjo, 2012) yang menyebutkan bahwa salah satu faktor yang dapat mempengaruhi perubahan perilaku ialah faktor penguat yang dalam hal ini ialah adanya tanda peringatan.

Perbedaan pada poin mengambil posisi secara salah ini dapat dipengaruhi oleh kurangnya kondisi fisik pada pekerja, hal ini terkait dengan kelelahan kerja. Seperti dijelaskan pada poin kegagalan dalam mengamankan, Kelelahan pekerja dapat mempengaruhi tingkat kewaspadaan pekerja akan bahaya yang ada pada pekerjaan yang dilakukannya (Kusumaningsari, 2014). Sehingga apabila kondisi fisik menurun terlebih pada shift malam, pekerja akan condong untuk melakukan unsafe action pada poin ini.

Berdasarkan observasi yang telah dilakukan diketahui bahwa unsafe action berupa bercanda saat bekerja juga mengalami perbedaan antara shift pagi, shift sore, dan shift malam hari. Pada malam hari unsafe action berupa bercanda saat bekerja lebih tinggi daripada shift pagi dan shift sore.

Bercanda saat bekerja tidak hanya dilakukan ketika dirinya bekerja namun juga mengganggu pekerja yang lain ketika melakukan pekerjaan. Pekerja mungkin tidak sadar bahwa ketika bekerja seorang pekerja harus fokus terhadap pekerjaan yang dilakukan agar mengurangi risiko human error/ kelalaian yang dapat menyebabkan kerugian bagi pekerja tersebut.

Perbedaan unsafe action pada poin bercanda saat bekerja ini dapat disebabkan oleh kurangnya pengawasan terkait dengan disiplin di tempat kerja, bahwasanya pekerja diperbolehkan bercanda hanya pada saat istirahat, sebaliknya apabila pekerja tengah melakukan pekerjaan maka pekerja dilarang untuk bercanda dengan teman kerjanya. Sayangnya pada shift sore dan malam tidak terdapat pengawasan terkait dengan keselamatan dan kesehatan kerja sehingga hal tersebut memicu meningkatkan kejadian unsafe action berupa bercanda saat bekerja.

Pada shift malam pekerja beranggapan bahwa dengan bercanda dengan temannya akan meningkatkan konsentrasi dan mengurangi rasa kantuk yang dialami oleh pekerja. Sehingga pekerja lebih memilih untuk bekerja sembari bercanda dengan temannya agar pada saat bekerja pada shift malam hari, pekerja tidak mengantuk dan tetap bersemangat dalam melakukan pekerjaannya. Padahal apabila pekerja bercanda saat bekerja, tentunya akan berdampak pada menurunnya tingkat kewaspadaan terhadap bahaya pada pekerjaannya dan nantinya akan mencelakakan dirinya sendiri. Menurut Santoni (2013), bercanda juga dapat menyebabkan kecacatan produk yang dihasilkan oleh pekerja.

Perusahaan dapat memberikan pengarahan pada pekerja apabila ingin bercanda dengan temannya yang bertujuan untuk menghilangkan rasa kantuk, pekerja dapat istirahat sejenak terlebih dahulu di tempat istirahat sembari mengobrol atau bercanda dengan teman yang juga melakukan istirahat atau tengah menunggu bahan yang akan dilakukan proses threading dari bagian pelurus. Sehingga tidak mengganggu pekerja lain yang sedang berkonsentrasi terhadap pekerjaan yang dilakukan.

Berdasarkan Tabel 4 tentang distribusi frekuensi unsafe action pada shift kerja pagi, sore, dan malam di PT X unit produksi I bagian threading tahun 2015 dapat diketahui bahwa frekuensi hasil observasi responden yang menyatakan unsafe action rendah terbanyak terdapat pada shift pagi, namun mengalami penurunan pada shift sore dan shift malam. Bahkan pada shift malam mulai ditemukan pekerja yang melakukan unsafe action dengan kategori tinggi.

Berdasarkan pembahasan yang telah dipaparkan di atas bahwa perbedaan unsafe action antar shift kerja dipengaruhi oleh beberapa faktor. Menurut teori Bird dan Germain (Budiono, 2003) menjelaskan bahwa terjadinya usafe action dapat dipengaruhi oleh faktor personal dan faktor pekerjaan. Faktor personal yang mempengaruhi perbedaan unsafe action pada shift pagi, sore dan malam adalah kurangnya kemampuan fisik dari pekerja. Sedangkan, faktor pekerjaan yang dapat mempengaruhi perbedaan unsafe action pada shift pagi, shift sore, dan shift malam ialah kurangnya pengawasan pada saat pekerjaan shift sore, dan shift malam.

Kurangnya kemampuan fisik pekerja yang terjadi khususnya pada shift malam hari dapat disebabkan oleh adanya siklus circadian rytme yang terjadi pada tubuh manusia. Menurut Maurits (2010), Circadian rytme adalah proses-proses yang saling berhubungan yang dialami tubuh untuk menyesuaikan dengan perubahan waktu selama 24 jam. Secara umum fungsi-fungsi tubuh manusia akan meningkat atau sedang pada puncaknya pada siang hari atau biasa disebut fase ergotropic, sedangkan fase thropotropic terjadi pada malam hari ketika fungsi dari tubuh mengalami penurunan dan kelelahan atau membutuhkan istirahat/pemulihan.

Menurunnya kondisi fisik pada pekerja shift malam dapat meningkatkan unsafe actioins yang 
dilakukan oleh pekerja. Pekerja yang kondisi fisiknya menurun akan memicu pekerja untuk berbuat ceroboh dalam melakukan pekerjaan. Menurut Fish dalam Firdaus (2005), menyatakan bahwa kinerja pada shift kerja malam mengalami penurunan akibat dari efek fisiologi, sehingga akan berpengaruh terhadap perilaku kewaspadaan pekerjaan termasuk aspek keselamatan. Bahakan dalam penelitian Kusumaningsari dkk (2014), juga menjelaskan bahwa adanya kelelahan kerja yang terjadi pada pekerja dapat mempengaruhi tingkat kewaspadaan yang dimiliki ole pekerja.

Kurangnya tingkat kewaspadaan dalam hal menanggulangi bahaya yang terdapat pada pekerjaan tentunya dapat berpengaruh terhadap tindakan yang berbahaya yang dilakukan oleh pekerja. Tindakan yang berbahaya ini tentunya akan meningkatkan risiko terjadinya kecelakaan yang terjadi pada pekerja khususnya pada bagian threading.

Selain dari faktor personal, meningkatnya unsafe action pada shift malam juga dapat dipicu oleh faktor pekerjaan yaitu kurangnya pengawasan. Pengawasan yang dilakukan oleh bagian safety pada bagian threading PT X hanya dilakukan pada shift pagi, sedangkan untuk shift sore dan malam hanya dilakukan oleh supervisor. Supervisor bagian threading hanya bertugas melakukan pengawasan terkait dengan kualitas hasil dari proses threading serta penerapan $5 \mathrm{R}$. Sedangkan pengawasan terkait dengan keselamatan dan kesehatan kerja tidak dilakukan pada shift sore dan shift malam. Oleh sebab itu pekerja pada shift kerja sore dan malam yang melakukan unsafe action meningkat dibandingkan dengan pekerja pada pagi hari melakukan pengawasan terkait unsafe action.

Pada dasarnya pengawasan terkait keselamatan dan kesehatan kerja dilakukan sebagai pengingat dan faktor pendorong agar pekerja selalu melakukan tindakan yang aman. Sehingga pekerja dapat terhindar dari semua hal yang dapat menyebabkan kerugian apabila bekerja dengan cara yang tidak aman. Dikarenakan dalam studi yang dilakukan Heinrich tahun 1928 pada 75 ribu kasus kecelakaan industri didapatkan bahwa $88 \%$ disebabkan oleh tindakan tidak aman, $10 \%$ oleh kondisi tidak aman dan $2 \%$ tidak dapat dihindarkan seperti bencana alam (Ramli, 2010). Sehingga tindakan tidak aman atau unsafe action menjadi faktor penting terjadinya sebuah kecelakaan.

Penjabaran di atas menunjukkan bahwa pengawasan terhadap keselamatan dan kesehatan kerja akan dirasa penting agar nantinya unsafe action yang dilakukan oleh pekerja dapat berkurang. Perusahaan dapat menanggulangi tidak adanya pengawas dari pihak HSE dengan cara meningkatkan koordinasi antara pihak HSE dengan supervisor dari bagian produksi. Dengan demikian pengawasan masih dapat dilakukan oleh supervisor bagian produksi terkait dengan keselamatan dan kesehatan kerja khususnya dalam hal unsafe action saat bekerja. Selain itu, perusahaan juga dapat memberikan pengarahan terkait istirahat pada pekerja khususnya yang bekerja pada shift malam. Pengarahan dilakukan agar pekerja dapat mengoptimalkan waktu luang ketika menunggu bahan yang akan dipahat dengan beristirahat sejenak untuk menjaga kondisi tubuh agar tidak mengalami kelelahan.

\section{SIMPULAN}

Dari hasil penelitian yang telah dilakukan pada pekerja shift bagian threading PT. X, didapatkan kesimpulan bahwa unsafe action yang dilakukan oleh pekerja pada bagian threading PT. X yang memiliki frekuensi terbesar ialah tidak menggunakan APD saat bekerja.

Penelitian ini juga menunjukkan bahwa adanya perbedaan unsafe action antar shift pagi, shift sore dan shift malam. Frekuensi unsafe action yang menyatakan rendah mengalami penurunan pada shift sore jika dibandingkan dengan shift pagi dan terjadi penurunan kembali pada shift malam. Serta, ditemukan pekerja yang melakukan unsafe action dengan kategori tinggi pada shift kerja malam, padahal unsafe action dengan kategori tinggi tidak ditemukan pada shift pagi dan shift sore.

Usaha yang dapat dilakukan perusahaan untuk mengurangi tingkat kejadian unsafe action pada pekerja, perusahaan dapat memberikan pengetahuan pada pekerja terkait dengan perbuatan unsafe action saat bekerja dan kerugian yang dapat ditimbulkan apabila melakukan perbuatan yang tidak aman di tempat kerja. Pengetahuan berjalan selaras dengan praktik penerapan tentang keselamatan kerja (Kurniawan, 2006). Selain itu, dalam rangka sebagai pengingat bagi pekerja, perusahaan dapat melakukan pemberian tanda peringatan dan tanda APD yang wajib digunakan ketika pekerja melakukan pekerjaan.

Perusahaan juga dapat memperbaiki dan meningkatkan sistem pengawasan terkait dengan unsafe action pada pekerja, serta meningkatkan koordinasi antar pengawas dari departemen HSE 
dengan pengawas pada bagian produksi supaya pengawasan terkait keselamatan kerja dapat merata pada tiap shift kerja karena pengawasan dapat dilakukan oleh pengawas bagian produksi.

Pekerja pada bagian threading khususnya yang bekerja pada saat shift malam diharapkan dapat memanfaatkan waktu istirahat seoptimal baik saat jam istirahat ataupun saat menunggu bahan yang akan diahat dari bagian pelurus. Hal itu bertujuan agar pekerja dapat mengurangi kelelahan yang terjadi akibat dari terganggunya circadian rhytm pada tubuh.

\section{DAFTAR PUSTAKA}

Budiono, A.M.S. 2003. Bunga Rampai Hiperkes dan KK Higiene Perusahaan Ergonomi Kesehatan Kerja Keselamatan Kerja, Semarang: Badan Penerbit Universitas Diponegoro.

Firdaus, H. 2005. Pengaruh Shift Kerja terhadap Kejadian Stres Kerja pada Tenaga Kerja di Bagian Produksi Pabrik Kelapa Sawit PTPN 4 Kebun Pabatu Tebing Tinggi Tahun 2005. Skripsi. Medan: Fakultas Kesehatan Masyarakat Universitas Sumatera Utara.

Gatipuri, Rona. 2011. Gambaran Tindakan Bahaya (Unsafe Action) dan Kondisi Bahaya (Unsafe Conditions) terhadap Risiko Terjadinya Kecelakaan Kerja di Divisi Kapal Niaga PT PAL (Persero) Surabaya. Skripsi. Fakultas Kesehatan Masyarakat Universitas Airlangga.

Insanno, J.S. 2015. Perbedaan Unsafe Actions dan Unsafe Conditions Antar Shift Kerja Pada Bagian Threading Unit Produksi I PT. X. Skripsi. Fakultas Kesehatan Masyarakat Universitas Airlangga.

Iqbal, M.S. 2014. Gambaran Faktor-Faktor Perilaku Penggunaan Alat Pelindung Diri (APD) Pada Pekerja di Departemen Metalforming PT. Dirgantara Indonesia. Jakarta: Skripsi. Universitas Islam Negeri Syarif Hidayatullah.

Jamsostek. 2012. Laporan Tahunan 2012. Diakses dari http://www.bpjsketenagakerjaan.go.id/page/
Laporan\%20Kinerja/Laporan-Tahunan-.html pada tanggal 26 November 2014.

Kurniawan, B., Lestantyo, D., Murtiningsih, D. 2006. Hubungan Karakteristik Pekerja dengan Praktik Penerapan Prosedur Keselamatan Kerja di PT. Bina Buna Kimia Urangan. Jurnal Promosi Kesehatan Volume 1 Nomor 2, p. 1-10.

Kusumaningsari, A., Suliantoro, H., Budiawan W. 2014. Pengaruh Distraksi dan Kelelahan Kerja terhadap Tingkat Kewaspadaan Masinis dan Asisten Masinis Kereta Api Kaligung Mas (Studi Kasus di PT. KAI DAOP IV Semarang). Industrail Engineering Online Journal Volume 3 Nomor 4, p. 1-10.

Maurits, L.S., Widodo I.D. 2008. Faktor dan Penjadualan Shift Kerja. Tekoi, Volume 13 Nomor 2, p. 1-4.

Maurits, L.S. 2010. Selintas tentang Kelelahan Kerja. Yogyakarta: Amara Books.

Notoatmodjo, S. 2012. Promosi Kesehatan dan Perilaku Kesehatan. Jakarta: Rineka Cipta.

Ramli, S. 2010. Sistem Manajemen Keselamatan dan Kesehatan Kerja (OHSAS 18001), Seri Manajemen K3, PT Dian Rakyat, Jakarta.

Suma'mur. 2009. Higiene Perusahaan dan Kesehatan Kerja (Hiperkes). Jakarta: Sagung Seto.

Tanjong, S.D. 2013. Implementasi Pengendalian Kualitas dengan Metode Statistik pada Pabrik.

Spareparts CV Victory Metallurgy Sidoarjo. Jurnal Ilmiah Mahasiswa Universitas Surabaya Volume 2 Nomor 1, p. 1-11.

Undang-Undang No. 1 Tahun 1970 Tentang Keselamatan Kerja.

Wijaya, Maurits, L.S., Suparniati, E. 2006. Hubungan antara Shift Kerja dengan Gangguan Tidur dan Kelelahan Kerja Perawat Instalasi Rawat Darurat Rumah Sakit Dr. Sardjito Yogyakarta. Tesis. Yogyakarta: Universitas Gajah Mada.

Wijono, S. 2006. Pengaruh Kepribadian tipe A dan Peran terhadap Stres Kerja Manajer Madya. Skripsi. Surabaya: Universitas Airlangga. 